\title{
Reserves Estimation for Coalbed Methane Reservoirs: A Review
}

\author{
Ali Altowilib, Ahmed AlSaihati, Hussain Alhamood, Saad Alafnan * and Sulaiman Alarifi \\ College of Petroleum Engineering \& Geosciences, King Fahd University of Petroleum and Minerals (KFUPM), \\ Dhahran 31261, Saudi Arabia; g201803820@kfupm.edu.sa (A.A.); g200780390@kfupm.edu.sa (A.A.); \\ g201704670@kfupm.edu.sa (H.A.); salarifi@kfupm.edu.sa (S.A.) \\ * Correspondence: safnan@kfupm.edu.sa
}

Received: 11 September 2020; Accepted: 17 December 2020; Published: 18 December 2020

\begin{abstract}
A continuous growth in the global economy and population requires a sustainable energy supply. Maximizing recovery factor out of the naturally occurring hydrocarbons resources has been an active area of continuous development to meet the globally increasing demand for energy. Coalbed methane (CBM), which is one of the primary resources of natural gas, associates complex storage mechanisms and requires some advanced recovery techniques, rendering conventional reserve assessment methods insufficient. This work presents a literature review on CBM in different aspects. This includes rock characteristics such as porosity, permeability, adsorption capacity, adsorption isotherm, and coal classification. In addition, CBM reservoirs are compared to conventional reservoirs in terms of reservoir quality, reservoir properties, accumulation, and water/gas saturation and production. Different topics that contribute to the production of CBM reservoirs are also discussed. This includes production mechanisms, well spacing, well completion, and petrophysical interpretations. The main part of this work sheds a light on the available techniques to determine initial-gas-in-place in CBM reservoirs such as volumetric, decline curve, and material balance. It also presents the pros and cons of each technique. Lastly, common development and economic challenges in CBM fields are listed in addition to environmental concerns.
\end{abstract}

Keywords: coalbed methane; natural gas; reserve estimation; organic materials

\section{Introduction}

Continuous growth in the global economy and population requires a sustainable energy supply. Table 1 shows the global primary energy consumption, measured in terawatt-hours (TWh) with crude oil, natural gas, and coal being key suppliers [1].

Table 1. The global primary energy consumption by 2018 [1].

\begin{tabular}{c|c}
\hline Data Item & Contribution to Global Energy Consumption (TWh) \\
\hline crude oil & 50,000 \\
natural gas & 40,000 \\
coal & 40,000 \\
traditonal biofuels & 24,000 \\
others & $>10,000$ \\
\hline
\end{tabular}

Petroleum engineers are always in a race towards maximizing recovery factor out of conventional and unconventional reservoirs (tight gas and oil, coalbed methane, shale gas and oil, heavy oil, and gas hydrate formations) in order to meet such demand. Extraction of gas generated and stored inside coalbeds, also known as coalbed methane (CBM), is one of the tools to meet global energy demand. This is mainly due to the large number of deposits of CBM scattered around the globe. CBM can be 
found in Australia, the United Kingdom, United States, Canada, and India [2]. The US has produced more than $1000 \mathrm{Bcf}$ in 2017 [3]. It is worth mentioning that CBM is considered a clean-burning fuel since it minimizes greenhouse emissions and lowers air pollution [4].

\section{Literature Review}

This section presents a literature review on coalbed methane from different aspects. This includes reservoir and flow characteristics along with methods of reserves estimation for coalbed reservoirs.

\subsection{Coalbed Methane Formation Characteristics}

Coal is unique since it acts as a source rock and a reservoir rock for light gases generated inside. These gases include methane, ethane, carbon dioxide, nitrogen, and hydrogen sulfide. The generation of coalbed methane is done through biogenic (metabolic activities of microbes) or thermogenic processes (due to increasing depth, pressure, and temperature) occurring throughout the diagenetic cycle. Generated methane is usually adsorbed on the surface of the coal, mainly in micropores. Adsorption can be defined as a process in which gas molecules adhere to the internal surface of a coalbed.

In CBM reservoirs, the force that keeps the methane trapped inside the coalbed is the hydraulic pressure; in order for $\mathrm{CBM}$ to be produced, there should be natural fractures or cleats connecting the pores to the well. These cleats are formed as a result of regional and structural events. Cleats can also be destroyed by burial or mineralization [5]. What is also unique about coal is that it has the capability of adsorbing massive quantities of gas molecules due to large porosity with low permeability. The gas saturation is affected by pressure, temperature, and fracturing degree [6-8].

The mechanism of producing methane depends largely on the hydraulic pressure and the concentration of water and gas inside the bed. A reduction in the water content results in the release of gas. The dewatering process reduces the partial pressure in the cleat and results in the desorption of gas from the coal matrix and diffusion towards the cleat/fracture and then to the well. Moreover, the continuous reduction in water saturation shifts the relative permeability curves favoring the transport of methane in the larger pores. Dewatering simultaneously enhances desorption/diffusion from micropores and advection in larger pores and cracks. Ultimately, methane production sharply increases and water decreases.

\subsection{Porosity}

CBM reservoirs have been considered as dual or tri-porosity systems in the literature: cleats (macropore) and matrix (micropore). The cleats help in flowing the gas, whereas the matrix enhances gas storage. The majority of the porosity in CBM comes from the matrix, ranging from 10 to $20 \%$. Cleat matrices are usually filled with water and have a porosity in the range of $0.1-1 \%$ [9]. Even though the value is small, it directly contributes to production. Figure 1 shows the CBM porosity system with the mechanism involved inside it. The matrix of CBM has a higher storage capacity compared to conventional reservoirs due to having pores with larger surface areas [10].

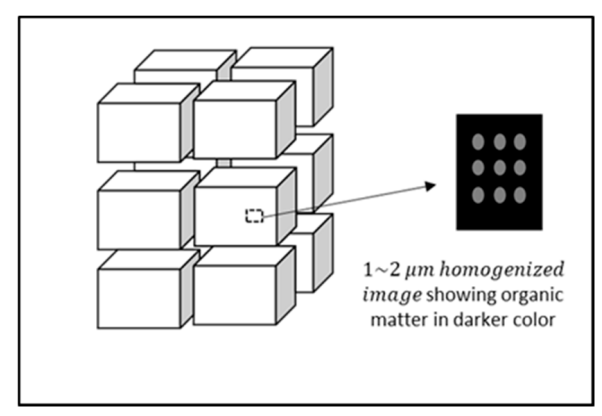

Figure 1. Coalbed methane (CBM) Dual-Porosity System. 


\subsection{Adsorption and Sorption Isotherm}

Coal has an adsorption capacity that can be defined as the volume of adsorbed gas in standard cubic feet divided over the mass of coal in tons. The amount of gas adsorbed depends enormously on the quality of coal [11]. At constant temperature, gas pressure and coal capacity or the volume of methane stored can be related to each other using Sorption or Adsorption Isotherm. Adsorption Isotherm is determined by conducting lab experiments on CBM cores. Something to note about Adsorption Isotherm is that the results are affected by the applied temperature, moisture, and mineralogy of the used sample. Moreover, results from this curve indicate the maximum amount of methane adsorption but not necessarily the actual total methane existing in the tested core. A key difference between Sorption Isotherm and Adsorption Isotherm is that the first one includes adsorbed gas, compressed, or free gas, whereas the second accounts for adsorbed gas only [10]; a distinction that is needed in some reserve estimation models where input parameters are either based on sorption or adsorption is detailed in subsequent sections.

\subsection{Coal Classification}

Coal composition (type), maturity (rank), and grade (purity) all affect the methane sorption capacity. Coal is made of three types of macerals, namely vitrinite, liptinite (exinite), and inertinite [11-15]. The rank of coal is considered a qualificative description of coalification, a process that involves the decay of organic matter through biochemical and metamorphic transformation [12]. Table 2 shows the properties of different ranks [12-14]. The higher the rank, the higher the gas content, and the deeper the coal formation [14]. Coal purity is reflected in the term grade, which is based on chemical analysis to determine how much organic material exists in the tested coal [15].

Table 2. Coal Rank [12-14].

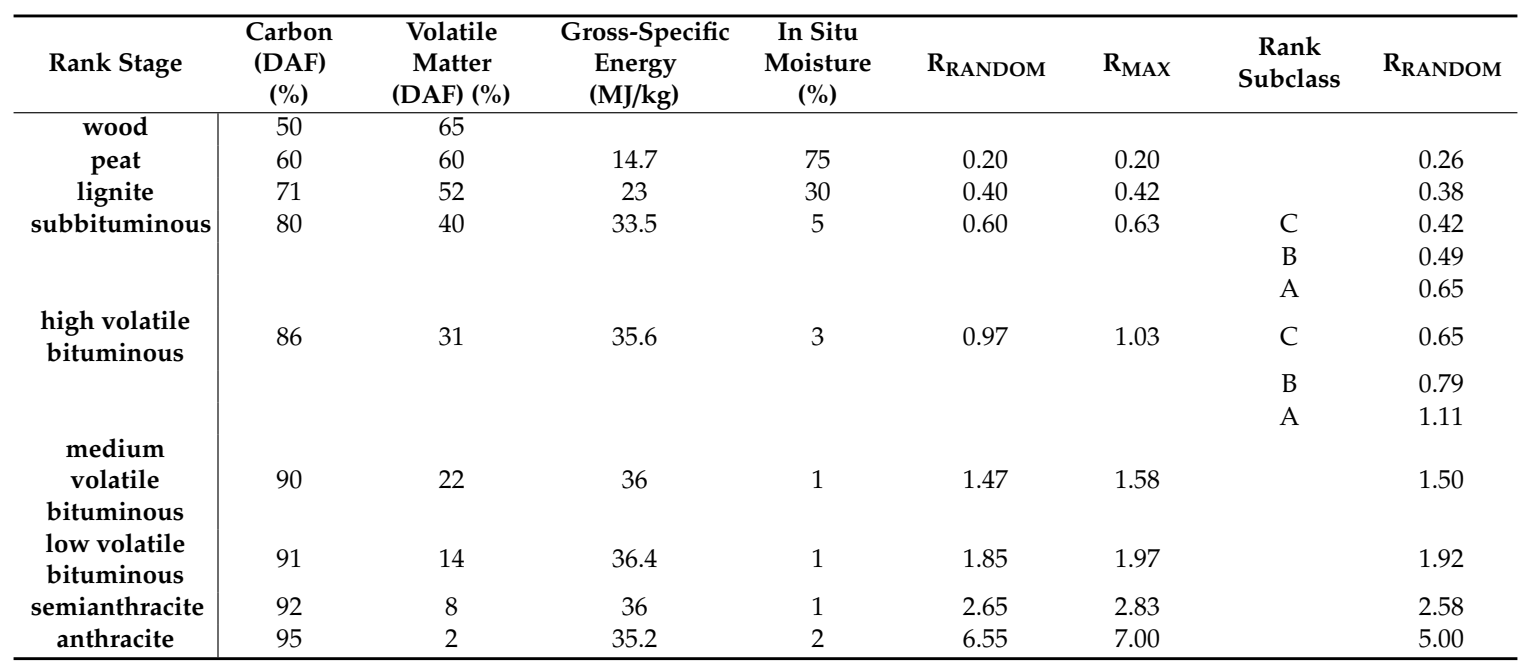

\subsection{Coal Permeability}

The permeability of coal is controlled by two cleat systems known as face and butt cleats. Face and butt cleats are formed 90 degrees to each other and as well as to the bed [11]. Face cleats have higher capability of drainage compared to butt cleats. As mentioned above, micropores have a large surface area. However, they have low permeability, which prevents the entrance and flow of fluid. However, through the diffusion process, desorbed gas can flow through the primary pores. On the other hand, cleat or fractures (macropores) are permeable and act as a sink to the micropores and conduits to the wellbore. [16,17] The typical range of permeability encountered in coal is from 1 to $60 \mathrm{mD}$, with higher and lower values attributed to the presence of natural fractures and nanopores, respectively [17]. 
Similar to conventional reservoirs, cleats or fractures are subjected to a reduction in permeability or closure due to confining stress.

Obtaining fluid and rock properties is essential towards understanding CBM reservoir properly. Table 3 shows the techniques of obtaining different reservoir properties for CBM reservoirs, whereas Table 4 shows different lab analyses conducted on coal samples [18].

Table 3. CMB Reservoir Data Acquisition Methods [18].

\begin{tabular}{cc}
\hline Data Item & Primary Source (s) \\
\hline permeability & Well test \\
initial pressure & Well test \\
initial water saturation & Well test \\
gas desorption pressure & Well test \\
pore compressibility & Well test \\
desorption isotherm & Core test \\
sorbed gas content & Core test \\
desopation time & Core test \\
relative permeability & Production data and core test \\
porosity & Core test \\
net pay thickness & Well log and core test \\
temperature & Well log \\
gas pvt properties & Gas analysis \\
water pvt properties & Water analysis \\
completion effectiveness & Well test \\
well drainage area (spacing) & Geologic description \\
\hline
\end{tabular}

Table 4. CMB Reservoir Data Acquisition Methods [15].

\begin{tabular}{ll}
\hline \multicolumn{1}{c}{ Analysis } & \multicolumn{1}{c}{ Results and Purpose } \\
\hline gas content & $\begin{array}{l}\text { Provides volumes of desorbed gas (from coal samples placed in canisters), } \\
\text { residual gas (from crushed coal), and lost gas (calculated). The sum of these is } \\
\text { the in situ gas content of a given coal seam. }\end{array}$ \\
\hline gas composition & $\begin{array}{l}\text { Determines the percentage of methane, carbon dioxide, nitrogen, and ethane in } \\
\text { the desorbed gas. Used to determine gas purity and to build composite } \\
\text { desorption isotherms. }\end{array}$ \\
\hline core description & $\begin{array}{l}\text { Visually captures coal brightness, banding, cleat spacing, mineralogy, } \\
\text { coal thickness, and other factors. Provides insights about the composition, } \\
\text { permeability, and heterogeneity of a coal seam. }\end{array}$ \\
\hline adsorption isotherm & $\begin{array}{l}\text { A relationship, at constant temperature, describing the volume of gas that can be } \\
\text { sorbed to a surface as a function of pressure. Describes how much gas a coal } \\
\text { seam is capable of storing and how quickly this gas will be liberated. }\end{array}$ \\
\hline proximate analysis & $\begin{array}{l}\text { Provides the percentage of ash, moisture, fixed carbon, and volatile matter. } \\
\text { Used to correct gas contents and sorption isotherms to an ash-free basis, correct } \\
\text { the isotherms for moisture and determine the maturity of high-rank coals. }\end{array}$ \\
\hline ultimate analysis & $\begin{array}{l}\text { Determines the percentage of oxygen, carbon, hydrogen sulfur, and nitrogen. } \\
\text { Used primarily to assess coal maturity. More commonly used in the mining } \\
\text { industry for CMB projects. }\end{array}$ \\
\hline \multirow{2}{*}{ bulk density } & $\begin{array}{l}\text { A value indicating the amount of incidental light reflected by the vitrinite } \\
\text { maceral. This technique is a fast and inexpensive means of determining coal } \\
\text { maturity in higher rank coals. }\end{array}$ \\
\hline & $\begin{array}{l}\text { Captures the types, abundance and spatial relationships of various maceral } \\
\text { types. These differences can be related to differences in gas-sorption capacity } \\
\text { and brittleness, which affect gas content and permeability. }\end{array}$ \\
\hline $\begin{array}{l}\text { Relationships between bulk density and other parameters (such as ash content } \\
\text { and gas content) can be used to establish a bulk-density cut-off for counting coal } \\
\text { and shale thicknesses using a bulk-density log. }\end{array}$ \\
\hline
\end{tabular}




\section{Differences between CBM and Conventional Reservoirs}

Coal seams are appreciated as a reservoir and a significant source of methane due to the fact that they store six to seven times more $\mathrm{CH}_{4}$ than conventional gas reservoir. The $\mathrm{CBM}$ gas is found in three different forms: (i) free gas, (ii) dissolved gas in the associate coal water, and (iii) absorbed gas on the solid surface of the coal. Regardless of the immense quantity of methane in coal seams; it has special features that make it distinctive from that in other conventional oil and gas reservoir. This is due to the infinitesimal porosity and permeability nature of coal seams [19].

\subsection{Reservoir Properties}

Unlike conventional oil and gas reservoirs, where the matrix is not organic in nature, the matrix of CBM reservoir is organic and contains $10-30 \%$ inorganic ash. The coal matrix is classified as brittle and friable due to low Young's modulus values and a high poison ratio [20]. The amount of gas content in a coal seam is determined by the coal's rank, which is measured by the quality and thermal maturity of the organic material [19].

\subsection{Gas Accumulation}

Hydrocarbon gasses are stored in the conventional reservoir in a way that differs from that in a coal seam. In the conventional reservoir, free hydrocarbon gases fill the available spaces between the sand grain particles, whereas in a coal seam, the hydrocarbon gas is clutched to the solid surface in copious micropores by a process called adsorption. The large amount of stored gas in the coal system is because of the large surface area in the micropores and the closeness of the methane molecules in the solid surface. Some of the free gas exists in the cleat of coal, while some methane is dissolved in the water. The adsorption process that takes place in a coal system creates large gas storage in coal systems with an effective porosity less than $2.5 \%$; the majority of methane is stored in the micro- and meso-porous constituents as a sorbed gas [19]. Moreover, the storage capacity is highly influenced by the origin and the maturation of organic matter. The adsorption capacity positively correlates with maturation as reported by different studies [20-22].

\subsection{Water Production}

In contrast to methane in a conventional gas reservoir, methane in CBM is dissolved in the water formed from natural fractures in the coal. For the methane to be adsorbed from the coal matrix, this water formation has to be thoroughly removed. The prolific production of water normally occurs in the first or second year of production followed by a significant decrease in volume for the remaining life of the well. On the contrary, a conventional reservoir naturally keeps the water of the pore spaces fixed, and its production will not be assumed until the aquifer is encroached, which indicates a looming stoppage of gas production [19].

\subsection{Gas Production}

The development of gas in a CBM has many similarities to its development in a conventional reservoir. Nonetheless, the undeniable differences have an extensive impact on operations and profitability. The pattern of gas production is another distinct feature that contrasts CBM wells from conventional reservoir wells.

\subsection{Coal Reservoir Analysis Permeability}

This is the most important factor that significantly affects the economic viability of a gas containing coal. Nevertheless, it is the most challenging parameter to assess precisely. Coal in its natural form has a very low permeability, and its permeability is all due to the existing fractures. Furthermore, the degree of fracture aperture opening, direction of face and butt cleats, saturation of formation water, depth of burial, and the shrinkage of matrix associated with desorption and in situ stresses are all crucial 
elements that can alter the permeability as well. The difficulty of accurate evaluation of the permeability is due to the fact that collected samples/cores for core tests are not usually representative $[23,24]$

\section{CBM Production}

\subsection{Production Process}

The flow process of CBM production is similar to the dual-porosity system derived by Warren and Root. A CBM is a system of matrix blocks that are surrounded by fractures, namely cleats. The fluid is drained from the matrix into the cleats, which are connected to the wellbore [25]. The sorbed methane in the coalbeds is regulated by the water pressure gradient. Methane stays in the coalbed as the water table remains above the gas-saturated coal. If the water table is lowered for any reason, the stored methane will be released into the atmosphere. Cleats must exist to allow for connectivity between sorption sites. If the coal beds are deep, cleats might get closed as a result of overburden stress [26].

The production profile for CBM system exhibits water production from the cleats, where the production behavior is governed by Darcy's Law. Then, as the pressure in the system declines, the gas starts to be desorbed from the matrix, causing the gas and water to flow through the cleats system as a result of the concentration difference. The water production rate decreases as the gas production increases until the gas peak is achieved. The production behavior in this stage is dictated by a diffusion process. Then, as the matrix shrinks as a result of pressure depletion, which causes the porosity and permeability in the system to reduce, the gas production rate decreases. $[25,27]$

\subsection{Production Technology}

As mentioned in the previous section, CBM systems are different from conventional gas reservoirs. Thus, the technique used to drill and complete CBM wells must take account of these differences. Early coalbed methane wells are used to complete the well with open-hole completion, which means basically drilling to the burial depth and enlarging the hole beneath the previous casing to remove any damage that might have occurred while drilling operation. However, this technique is still associated with fine production [26,28]. For example, it was challenging to produce from San Juan Basin at the early stage of the project due to drilling activities, as the latter damaged the brittle reservoirs, causing coal fines production, which in turn clogged the surface equipment [29]. A new technique is now used that aims to isolate the reservoir by a cemented casing, where the methane flows into the well through small holes, namely perforations made in the casing.

It was observed that open-hole completions are not as successful as cased-hole completions [30]. The disadvantage associated with the cemented casing completion type is that the cement can invade the cleat structure and cause potential damage [31]. In addition, when the cemented casing is perforated, rubble from the friable coal might be formed due to explosive charges, which might cause the perforations to be plugged. Another way to complete CBM wells is by making a cut through the casing and cement and into the reservoir by using a hydraulic jetting tool, which flushes the coal material away from the fluid conduit. Lambert [32] ranked the cemented casing type of completion as the most suitable compared to others. The only drawback is the possibility of restricting the inflow flow around the wellbore due to debris.

\subsection{Well Spacing}

The well position and spacing in CBM are of prime importance in obtaining the maximum recovery [33]. Conventionally, if the wells are not properly distant, then they compete to deplete the drainage area [34]. However, in CBM wells, closer well spacing causes an additional pressure drop and increases the desorption rate and thereby more gas production. Zuber et al. [35] showed that the optimum well spacing is a function of permeability. Thus, wells with low permeability need to be even closer. They stated that closer wells archive high production gas rates at an early stage, while wider, distant wells result in a better return in the long-term. Thus, producers prefer wider wells spaced out 
in an attempt to save on the drilling and production cost. To drill wells with a close distance mandates a large area to accommodate the number of wells; therefore, CBM development is appropriate in a highly populated area. Alternatively, drilling fewer wells assisted by hydraulic fractures can assure reaching the required pressure drop to desorb methane [35]. The production can be further augmented by targeting natural fractures to create a network of interconnected fractured systems. The integrity of the natural fracture can be sustained by the injection of graded proppant for higher connectivity throughout the production span.

\subsection{Open Hole Cavity}

The open-hole cavity completion, which is called stress relief, has been used in the San Juan Basin. The technique involves injecting the well with compressed air or air/water for about six hours. Once the injection process is terminated, the well is open to the atmosphere and pressure reduces rapidly. The process is repeated until the wellbore is full of solids, which are then circulated out by air and frequent water sweeps [36]. The open hole cavity technique is considered as stimulation since it enhances the permeability near the coal seam and removes the formation damage due to drilling activities. The magnitude of vertical stress, i.e., the overburden, above the cavity is distributed equally on each side of the created cavity. As a result, the coal fails and moves toward the cavity. In general, the shear failure around the cavity is not more than two cavities in diameter. The increased conductivity is extended more than $90 \mathrm{~m}$ into all sides of the cavity. The reduction in stress thereby widens the fractures and increases the permeability.

\subsection{Coal Seam Stimulation Techniques}

The techniques used in CBM stimulation can be categorized into three classes [37]: (i) mechanical stimulation, which includes hydraulic fracturing technique and formation blasting; (ii) thermal stimulation, such as using the cryogenic liquid nitrogen and heating, which intends to increase the rate of methane desorption, deteriorate the integrity of coal body, and weaken the mechanical strength of the coal as a result of temperature effect, which in turns lead to an improvement of permeability; (iii) chemical stimulation, such as acidification and microbial stimulation techniques, which focus mainly on dissolving the minerals in the coal to alter the porosity and enhance permeability.

\subsubsection{Hydraulic Fracturing}

Hydraulic fracturing involves injecting fluids containing proppant at high pressure into the coal seam system. The hydraulic fluid is then pushed further to increase the geometry of the primary fracture, which can intersect with a secondary fracture, causing an improvement of the permeability [38]. The effect of the hydraulic fracturing technique on gas production has been looked at extensively during the past few years. Presently, hydraulic fracturing has become a standard stimulation method for tight oil and gas reservoirs. There is a challenge associated with such a stimulation technique, that is, the permeability of the coal reaches a peak value just after the fracturing process, but then the gas recovery declines as a result of the closure of the initiated fracture [37]. Thus, different improved hydraulic fracturing techniques have been proposed to overcome the problem, such as a graded particle injection and pulse hydraulic fracturing [39-42].

\subsubsection{Blasting}

The deep-hole blasting technique involves using dynamite to act on the coal around a wellbore, causing damage to the mass of the coal and relief of stress around the borehole, which enhances the permeability. The deep-hole blasting technique can be divided into different types: (i) deep-hole presplit controlling blasting, (ii) deep-hole loose blasting, and (iii) energy-accumulated hydraulic blasting [43]. The affected zones of deep-hole blasting can be divided into three parts: crushed zone, fractured zone, and vibration zone. The permeability in the first two zones can be significantly improved. There are some obstacles associated with blasting technique, such as [37] (i) the inability to 
use deep-hole blasting in a high gas content coal seam; (ii) the possibility of causing roof and floor damage to the coal seam, which can make water to flow into the coal seam; and (iii) difficulty to construct an adequate borehole due to collapse, mainly in a soft coal seam.

\subsubsection{Cryogenic Liquid Nitrogen}

Conventional hydraulic stimulation methods use a large amount of water and can contaminate groundwater aquifers [8]. Therefore, many researchers have looked at the cryogenic liquid nitrogen stimulation technique. The cleat of the original coal seam has a large amount of water, and at low temperature, when water turns into ice, the volume increases by $9.1 \%$. Thus, the change of the phase can theoretically generate an expansion of pressure of $270 \mathrm{MPa}$. During the phase transition of water, the cryogenic liquid nitrogen is injected into the coal seam to fracture the coal medium, which enhances the coal permeability [44]. Furthermore, the liquid nitrogen gasification and low-temperature effect can damage the coal and create the fracture to increase the permeability. Although the liquid nitrogen technique can preserve water resources and reduce the reservoir damage, it also has some challenges compared to other techniques, such as (i) cost and (ii) faster closure of the initiated fracture due to the inability of the liquid nitrogen to carry proppant with low liquid viscosity.

\subsubsection{Heating}

Steam injection is used widely to stimulate an oil reservoir [45]. However, the rapid loss of heat can limit the stimulation efficacy as the depth increases [46]. Therefore, some works have been planned to use a microwave heating stimulation technique. This technique involves using microwave radiation to heat coal medium to enhance production. However, the high temperature eliminates the water in the void space, which increases the permeability. On the other hand, in a gas reservoir, the high temperature can eliminate the water-block effect and reduce gas adsorption capacity. There are some challenges associated with this technique, such as that (i) a robust microwave radiation antenna is needed, (ii) time and frequency are prerequisite parameters that must be known, and (iii) the range of microwave heating needs to be known. The subsurface heating element can be placed to increase the reservoir temperature, increasing desorption rate, reducing the condensation rate, and minimizing the molecular fractionation effect $[47,48]$. The rate of methane desorption can be enhanced further through coupling carbon dioxide injection with heating [49]. For sustainable production, a renewable source of energy for heating can be utilized [50].

\subsubsection{Acidification Reconstruction Coal Seam}

The channel of gas transport of the coal contains carbonate and clay minerals. The acid has the ability to dissolve the minerals and cause the matrix of the coal to swell and enhance the permeability. The acidification can be split into two types: (i) acidification with low pressure and (ii) acid fracturing. The low-pressure acidification process involves pumping the acid into the coal seam at a pressure below the pressure required to damage the coal. On the other hand, the acid fracturing is relatively similar to the hydraulic fracturing process. Nevertheless, few field trials of acidification reconstruction have been reported [51]. There are challenges associated with acidification, including (i) potential contamination of groundwater aquifers, (ii) corrosion of surface equipment, and (iii) unsuitability for coal seams that have low mineral content.

\subsubsection{Microbial Stimulation}

The microbial stimulation technique involves using the microbial to destroy the small molecular substances in a coal seam, which in turn enhances the permeability and gas production. However, few field applications of microbial stimulation have been reported [37]. There are some challenges associated with microbial stimulation, such as (i) an appropriate microorganism needing to be selected, (ii) the difficulty of degrading high-rank coal by microbial stimulation, (iii) the long time it takes to notice the effect of the stimulation. 


\section{Petrophysical Logs in CBM}

There are distinctive petrophysical properties of CBM wells, which include interval transit time (AC) spontaneous potential (SP), fluid resistivity (R), gamma rays (GR), density (DEN), and compensated neutron $(\mathrm{CNL})$, that can be measured by performing logging. To confirm the presence of CBM, DEN, GR, $\mathrm{CNL}, \mathrm{AC}$, and R can be studied. The physical features of CBM differ from other types of rocks, such as sandstone, and limestone; therefore, the log responds differently [52]. Seismic data can be utilized to characteristically distinguish coalbed methane from other lithologies, especially intrusions [52]. The AC, porosity, and $\mathrm{R}$ are relatively high in CBM reservoirs in comparison with conventional rock reservoirs. On the other hand, the DEN, SP, and GR are low compared to conventional gas reservoirs [53]. The aforementioned logs exhibit a characteristic response in CBM that is attributed to different factors such as the high organic matter contents, interpore connectivity, and multi-nature storage mechanisms; e.g., anthracite has an AC response of $350-450 \mu \mathrm{sm}^{-1}$. The CNL for CBM reservoirs varies between 30 and $50 \%$, which indicates high porosity. The DEN is less than $1.8 \mathrm{~g} / \mathrm{cm}^{3}$ due to the brittleness of CBM compared to conventional reservoir rock, with a DEN more than $2.3 \mathrm{~g} / \mathrm{cm}^{3}$. The GR ranges from 20 to 100 API.

\section{Methods of Estimating Initial Gas in Place (IGIP)}

There are several methods used to predict the Initial Gas in Place (IGIP) for coalbed methane. This part will illustrate the details and the restrictions of the available techniques such as volumetric methods and performance methods (decline curve and material balance) [54].

\subsection{Volumetric Method}

One of the methods that can be used to calculate the initial gas in place is the application of the volumetric estimation [55]. This method is used for conventional resource calculations, and it is considered simple as it does not require many data to calculate the initial gas in place. On the other hand, it is more likely to provide results with errors as it depends on primary parameters that are partially assumed such as the reservoir bulk volume and in situ gas content [56].

In order to predict the volume of the adsorbed gas in coal, several approaches have been developed. One of these approaches is the technique developed by Pope et al. [57], in which he measured the gas content based on the methane partial pressure. In Lamarre's approach, he calculated the gas content by assuming that the methane partial pressure is equal to the gas in solution, which is the produced water. This assumption requires the availability of sufficient coal isotherm. Another method is evaluating the bubble point pressure of the water in order to calculate the critical desorption pressure (CDP), which was developed by Carlson [58].

Determining the correct coal thickness is another challenge associated with the estimation of the adsorbed gas content in coal, which has a heterogeneous thickness along the reservoir. In many cases, the coal thickness is assumed to be equal to the reservoir thickness, which is usually measured from density logs. Another challenge that increases the uncertainty of the adsorbed gas calculations is measuring the natural fracture porosity and initial water saturation. Generally, these values are measured from core analysis, but they also have their share of difficulty and uncertainty [54].

Another part of calculating the initial gas in place by the volumetric method is the estimation of the free gas. The free gas quantity is usually considered very small compared to the adsorbed gas, but it has a major impact on calculating the total gas.

By combining both the volumes of the adsorbed gas in coal and the free gas, the total initial gas in place can be calculated volumetrically from the following equations [18]:

$$
\begin{gathered}
\text { Initial gas in place }=\text { Free gas }+ \text { Adsorbed gas } \\
\qquad G_{i}=G_{f}+G_{c}
\end{gathered}
$$




$$
G_{f}=\frac{43560 A h \phi_{f}\left(1-S_{w i}\right)}{B_{g i}}
$$

The gas content can be calculated by using the Langmuir equation:

$$
\begin{gathered}
G_{c}=\frac{V_{L} P}{P_{L}+P} \\
G_{i}=A h\left(\frac{43560 \phi_{f}\left(1-S_{w i}\right)}{B_{g i}}+1.3597 \rho_{c} G_{c}\right)
\end{gathered}
$$

where

$$
\begin{aligned}
& G_{i}=\text { Initial gas in place } \\
& A=\text { Drainage area, acre } \\
& h=\text { Thickness, } \mathrm{ft} \\
& \phi_{f}=\text { Natural fracture porosity } \\
& S_{w i}=\text { Initial water saturation } \\
& B_{g i}=\text { Initial gas formation volume factor, } \mathrm{ft}^{3} / \mathrm{scf} \\
& \rho_{c}=\text { bulk density of coal, } \mathrm{gr} / \mathrm{cm}^{3}, \mathrm{~kg} / \mathrm{m}^{3} \\
& G_{c}=\text { Adsorbed gas content, } \mathrm{scf} / \mathrm{to} \\
& G_{f}=\text { Free gas, scf } / \text { to } \\
& V_{L}=\text { Langmuir volume constant, scf } / \mathrm{ton}, \mathrm{scf} / \mathrm{ft}^{3} \\
& P=\text { Reservoir pressure, psia } \\
& P_{L}=\text { Langmuir pressure constant, psia }
\end{aligned}
$$

\subsection{Performance Methods}

The performance methods are the methods that depend on historical data of gas and water production to calculate the initial gas in place. The performance methods include two methods, namely the Decline Curve Analysis and Material Balance. These methods are based on the principle of water production reduction with time, which results in decreasing the reservoir pressure. This drop in the pressure allows the located gas in the matrices to be released. The gas production starts at a low flow rate since the pressure drop is still very small. The gas production increases with pressure reduction until it reaches the peak [59].

\subsubsection{Decline Curve Analysis}

Based on the method of decline curve analysis with the conventional resources, several models of the decline curve analysis have been developed for calculating the gas in place of the coalbed methane. Some of these models were created based on Arps's [60] empirical equation of the exponential, hyperbolic, and harmonic models. One of the issues with Arps's empirical model was that it did not match the transient flow period, which makes it unsuitable for modeling unconventional resources. This issue was solved by using the modified hyperbolic model [61], which changes the hyperbolic model into an exponential curve to match the curve of the historical production data during the transient flow period [62].

The modified hyperbolic model is given by the below equation:

When $D>D_{i}$ :

$$
q=\frac{q_{i}}{\left(1+b D_{i} t\right)^{\frac{1}{b}}}
$$

When at $D \leq D_{i}$ :

$$
q=q_{i} e^{\left(-D_{i}\right)}
$$


where

$q=$ Production rate

$q_{i}=$ Initial production rate at the beginning of the boundary-dominated period

$D=$ Nominal decline rate

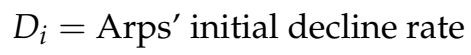

Stretched Exponential Decline Curve Model

The stretched exponential model is an empirical model that was developed based on the original Arps model [61]. Similar to the modified Arps model, the advantage of this model over the Arps model is that it can be applied for unconventional resources, including coalbed methane, where it has a good fitting for both the transient and the bounded flowing periods. This applies the idea of the modified hyperbolic model. This will benefit in the calculation of the estimated ultimate recovery (EUR) for the individual wells. [63] The stretched exponential decline model can be calculated from the following equation:

$$
q(t)=q_{i} e^{\left[-\left(\frac{t}{\tau}\right)^{n}\right]}
$$

where

$$
\begin{aligned}
& q(t)=\text { Production rate at time } t, \mathrm{scf} / \text { month } \\
& q_{i}=\text { Initial gas production rate, scf/month } \\
& t=\text { Time of production, month } \\
& n=\text { Exponential parameter } \\
& \tau=\text { Time parameter, month }
\end{aligned}
$$

\section{Duong Decline Model}

Another model that was developed to overcome the issue of modeling the transient flow period is the Duong model [64]. The Duong model displays a good match for long transient periods, which means that it can be applied to unconventional resources. Generally, the unconventional resources have low permeability in the pay zone and require hydraulic fracturing in order to have economical production rates. The Duong can be used to calculate the production rate and the cumulative production rates of coalbed methane from the following equations:

Gas Production Rate:

$$
q(t)=q_{i} t^{-m} e^{\frac{a}{1-m}\left(t^{1-m}-1\right)}
$$

Gas Cumulative Production Rate:

$$
G_{p}=\frac{q_{i}}{a} e^{\frac{a}{1-m}}\left(t^{1-m}-1\right)
$$

where

$q(t)=$ Production rate at time $t, \mathrm{~m}^{3} /$ day

$q_{i}=$ Initial gas production rate, $\mathrm{m}^{3} /$ day

$G_{p}=$ The cumulative gas production, $\mathrm{m}^{3}$

$t=$ Time of production, day

$a=$ Coefficient of the intercept

$m=$ The slope.

The plot of the relationship between $t$ and $q / G_{p}$ on a log-log plot is used to predict the basis of Duong's model. It can be observed from the plot that Duong's model is a linear model, which distinguishes this model from the other decline models. Duong's model may overestimate the well-estimated ultimate recovery (EUR) because of the variation of the flow regimes during the production period. 
Power-Law Decline Model (Ilk Model)

Based on the Loss-Ratio derivatives presented originally by Johnson and Bollens [65] and Arps [60], Ilk et al. [66] developed the Power-Law exponential decline model in 2008. This model is more suitable for representing the unconventional gas resources (including coalbed methane) than Arps' hyperbolic model. This model provides a better match for the decline curve for both the transient and the bounded periods in the tight gas formations (especially for the transient period), which means it can be utilized for the prediction of the unconventional reserves. The Power-Law decline model can be given by the following equation:

$$
q(t)=\hat{q}_{i} e^{\left[-\hat{D}_{\infty} t-\hat{D}_{i} t^{n}\right]}
$$

where

$$
\begin{aligned}
& q(t)=\text { Production rate at time } t \text {, Mscf/day } \\
& q_{i}=\text { The rate intercept, Mscf/day } \\
& \hat{D}_{i}=\text { The initial decline constant } \\
& \hat{D}_{\infty}=\text { Decline constant at infinite time }(t=\infty) \\
& t=\text { Time of production, day } \\
& n=\text { Time exponent. }
\end{aligned}
$$

\section{Logistic Growth Model}

By using the principle of population growth, Clark et al. [67] developed the logistic growth decline curve model to estimate the production from a single well. This model is also considered another solution for the original Arps model issue of predicting the flow in the transient period, which applies the fact that the logistic growth model can be applied for unconventional resources production performance. In addition, Clark et al. [67] have made some modifications to the original work in order to model the production rate and the cumulative production rate. The flow rate and the cumulative production rate are given by the following equations:

$$
\begin{gathered}
q(t)=\frac{K n a t^{n-1}}{\left(a+t^{n}\right)^{2}} \\
Q(t)=\frac{K t^{n}}{a+t^{n}}
\end{gathered}
$$

where

$$
\begin{aligned}
& q(t)=\text { Production rate at time } t, \text { Mscf } / \text { day } \\
& Q(t)=\text { The cumulative production at time } t \text {, Msc } \\
& K=\text { The recoverable resources } \\
& a=\text { constant } \\
& t=\text { Time of production, day } \\
& n=\text { Hyperbolic exponent. }
\end{aligned}
$$

\subsubsection{Gas Material Balance Equation (MBE)}

One of the most common methods used for the prediction of the Initial Gas in Place (IGIP) is the Material Balance Equation (MBE) method. Initially, this method was developed to calculate the gas reserves in the conventional volumetric reservoirs, as the material balance equation depends on the relationship between $p / Z$ and $G_{p}$ to predict the initial gas in place. This relationship can be obtained from the below equation [66]:

$$
\frac{p}{Z}=\frac{p_{i}}{Z_{i}}\left(1-\frac{G_{p}}{G}\right)
$$


where,

$$
\begin{aligned}
& p=\text { Reservoir Pressure, psia } \\
& p_{i}=\text { The initial reservoir pressure, psia } \\
& Z=\text { Gas compressibility factor } \\
& Z_{i}=\text { Gas compressibility factor at the initial reservoir pressure } \\
& G=\text { Initial gas in place, scf } \\
& G_{p}=\text { Produced gas, scf. }
\end{aligned}
$$

The plot of $p / Z$ vs. $G_{p}$ is commonly used to predict the original gas in place. Other driving mechanisms are not considered appropriate in this model. In addition, this model does not consider the adsorbed gas in coal, which is an important factor for estimating the initial gas in place of the coalbed methane, and neglecting its impact can lead to inaccurate results of estimating the reserves of CBM. Several modifications have therefore been applied to the gas material balance equation in order to find the most suitable model for different types of reservoirs, including CBM. Below are some of the modified models of the material balance equation for the CBM [68].

\section{King's Method}

In 1993, King [69] developed the method of material balance to predict the initial gas in place (IGIP) of CBM by assuming that the reservoir consists of two types of porosities (a dual-porosity reservoir). The two types are matrix porosity, where most of the adsorbed gas is located, and the natural fracture porosity, which contains most of the free gas. The existence of these two types of porosities creates a state of equilibrium in the reservoir between the adsorbed gas and the free gas. Furthermore, this method of material balance includes rock compressibility, water compressibility, and water production. The equation that describes the material balance by King's method is given by:

$$
G_{p}=\frac{V_{b 2} \phi_{i} Z_{S C} T_{S C}}{P_{S C} T}\left(\frac{P_{i}}{Z_{i}^{*}}-\frac{P}{Z^{*}}\right)
$$

where,

$G_{p}=$ Cumulative gas production, MMscf.

$V_{b 2}=$ Bulk volume of the matrix porosity, $\mathrm{ft}^{3}$

$P=$ Reservoir pressure, psia

$P_{i}=$ The initial reservoir pressure, $\mathrm{psia}$

$P_{S C}=$ Standard pressure, psia

$Z^{*}=$ Gas compressibility factor for unconventional gas reservoir, dimensionless

$Z_{i}^{*}=$ Initial gas compressibility factor for unconventional gas reservoir, dimensionless

$Z_{S C}=$ Standard gas compressibility factor, dimensionless

$T=$ Reservoir temperature, ${ }^{\circ} \mathrm{R}$

$T_{S C}=$ Standard temperature, ${ }^{\circ} \mathrm{R}$.

In order to calculate the initial gas in place by using King's method, several iterations must be conducted. The process of King's method begins with the estimation of the average water saturation $\left(\overline{S_{w}}\right)$ by assuming a value of the matrix bulk volume $\left(V_{b 2}\right)$. The calculation of the average water saturation is given by the following equation:

$$
\overline{S_{w}}=\frac{S_{w i}\left[1-c_{w}\left(P_{i}-P\right)\right]+\frac{5.615\left(W_{e}-B_{w} W_{p}\right)}{\phi_{i} V_{b 2}}}{\left[1-c_{f}\left(P_{i}-P\right)\right]}
$$

where 


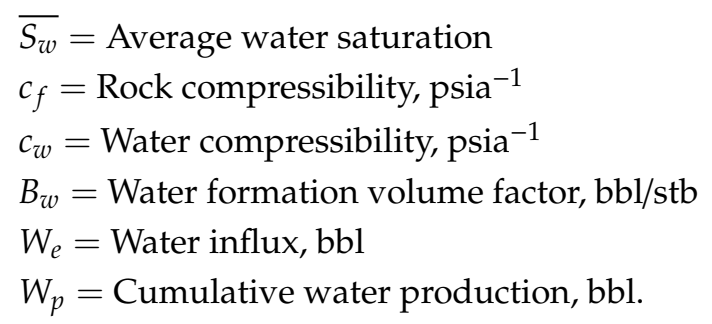

The resulted value of the average water saturation $\left(\overline{S_{w}}\right)$ is used to calculate the gas compressibility factor $\left(Z^{*}\right)$, which is given by the below equation:

$$
Z^{*}=\frac{Z}{\left[1-c_{f}\left(P_{i}-P\right)\right]\left(1-\overline{S_{w}}\right)+\frac{Z T P_{S C}}{Z_{S C} T_{S C}} \frac{C_{V L}}{\phi\left(P_{L}+P\right)}}
$$

where

$C_{V L}=$ Langmuir isotherm volume constant, $\mathrm{scf} / \mathrm{ft}^{3}$.

This procedure should be repeated for several of $V_{b 2}$ assumed values in order to create the plot of $P / Z^{*}$ vs. $G_{p}$, which is a straight-line plot.

After this, other values of $V_{b 2}$ should be calculated using the below equation:

$$
V_{b 2}=-m P_{S C} \frac{T}{\phi_{i} Z_{S C} T_{S C}}
$$

where

$m=$ The slope of the $P / Z^{*}$ plot.

By completing this part, two sets of $V_{b 2}$ values will be allocated (assumed and calculated). By plotting the two sets of $V_{b 2}$ versus each other, the actual value of $V_{b 2}$ can be estimated by assigning the intersection of the plot through the origin. By using the actual value of $V_{b 2}$, the initial gas in place can be calculated.

Jensen and Smith Method

Jensen and Smith [70] developed the following equation in 1997 to predict the initial gas in place (IGIP) of CBM:

$$
\frac{p}{p_{L}+p}=\frac{-1}{1.3597 V_{L} A h \rho_{c}} G_{p}+\frac{p}{p_{L}+p_{i}}
$$

where,

$p_{L}=$ Langmuir pressure constant, psia

$V_{L}=$ Langmuir volume constant, scf/ton

$\rho_{c}=$ Coal bulk density, $\mathrm{g} / \mathrm{cm}^{3}$.

Jansen and Smith's method was developed based on some simplified assumptions such as a volumetric reservoir; no storage of the free gas, which means neglecting the water storage in the natural fractures; and that the coal is saturated with the adsorbed gas in a single layer (monolayer), which is described by Langmuir Isotherm model.

This method is similar to the $p / z$ vs. $G_{p}$ method to calculate the IGIP for conventional resources. By plotting $\frac{p}{p_{L}+p}$ vs. $G_{p}$, the IGIP can be estimated from the intercept with the $x$-axis.

Seidle Method

In 1999, Seidle [71] modified King's method in order to achieve a simpler approach by neglecting formation compressibility, water compressibility, and water influx. By applying these changes, 
Seidle aimed to create a method with more precision of the IGIP estimation. Predicting the IGIP by Seidle method begins by plotting the resulting $p / Z^{*}$ vs. $G_{p}$ values from the below equation:

$$
\frac{P}{Z^{*}}=\frac{P_{i}}{Z_{i}^{*}}-\frac{P_{i}}{Z_{i}^{*} G_{i}} G p
$$

where the gas compressibility factor is calculated from the below equation:

$$
Z^{*}=\frac{Z}{\left(1-S_{w}\right)+\frac{0.031214 Z T P_{S C} V_{m p c}(1-a) \rho_{b} b}{Z_{S C} T_{S C}(1+b P) \phi}}
$$

The water saturation $S_{w}$ in the previous equation is given by the following equation:

$$
S_{w}=S_{w i}-\frac{5.615 W_{P}}{\phi A h}
$$

The drainage area $A$ is calculated from the below equation:

$$
A=\frac{-P_{S C} T}{m \phi A h Z_{S C} T_{S C}}
$$

where,

$V_{m p c}=$ Pure coal Langmuir volume constant, scf/ton

$a=$ Mass fraction of ash constant

$b=$ Langmuir pressure constant, pisa $^{-1}$

$\rho_{b}=$ Bulk density of coal, $\mathrm{gm} / \mathrm{cm}^{3}$.

Similar to King's method, several iterations are required to calculate the actual drainage area, which will be used in the following equation in order to create $p / Z^{*}$ vs. $G_{p}$.

$$
G_{p}=\frac{A h \phi Z_{S C} T_{S C}}{P_{S C} T}\left(\frac{P_{i}}{Z_{i}^{*}}-\frac{P}{Z^{*}}\right)
$$

After completing the plot, the IGIP for the CBM can be predicted from the resulting straight line and its intercept.

\section{Clarkson and McGovern Method}

The Clarkson and McGovern method was developed in 2001 [72]. This method is a modification of the Jensen and Smith method, such that it includes free gas storage. This modification provides more accuracy in the estimation of the IGIP for the CBM, where the free gas is considered a major part of the CBM reserves. The Clarkson and McGovern method is given by the following equation:

$$
\frac{p}{p_{L}+p}+\frac{32,037 \phi\left(1-\overline{S_{w}}\right)}{V_{L} B_{g} \rho_{c}}=\frac{-0.7355}{V_{L} A h \rho_{c}} G_{p}+\left[\frac{p}{p_{L}+p_{i}}+\frac{32,037 \phi\left(1-S_{w i}\right)}{V_{L} B_{g i} \rho_{c}}\right]
$$

This equation is used to create a plot of $\frac{p}{p_{L}+p}+\frac{32,037 \phi\left(1-\overline{S_{w}}\right)}{V_{L} B_{g} \rho_{c}}$ vs. $G_{p}$, which requires the determination of the free-gas-saturated porosity, gas properties, coal density, and Langmuir volume. The IGIP is predicted from the resulting straight line and its intercept.

Although Clarkson and McGovern have included the water saturation in the above-mentioned equation, they assume constant water saturation in their calculation in order to avoid the iteration process. 
Ahmed's Method

In 2006, Ahmed [73] developed a new approach to the material balance method. The advantage of Ahmed's method is its inclusion of the initial free gas, water expansion, formation compaction, and Langmuir isotherm in the equation. In addition, the development of this method has ended the necessity of the iteration process to calculate the drainage area. In addition, Ahmed's method was divided into two cases, where one of them includes the rock and fluid compressibility, and the other neglects them.

(1) Neglecting rock and fluid compressibility:

The material balance equation for this case of Ahmed's method is given by:

$$
G_{p}+B_{w} W_{p} E_{g}=A h\left[1359.7 \rho_{B}\left(G_{c}-V\right)-7758 \phi\left(1-S_{w i}\right) E_{g}\right]+7758 A h \phi\left(1-S_{w i} E_{g i}\right)
$$

where,

$E_{g}=$ Gas expansion factor at the reservoir pressure, scf/bbl

$E_{g i}=$ Initial gas expansion factor, scf/bbl

$G_{c}=$ Coal-gas constant, scf/ton

$\rho_{b}=$ Bulk density of coal, $\mathrm{gm} / \mathrm{cm}^{3}$

$V=$ Gas content at pressure $\mathrm{p}$, scf/ton. $V$ is calculated by the following equation:

$$
V=V_{m} \frac{b P}{1+b P}
$$

where,

$V_{m}=$ Langmuir's constant.

$b=$ Langmuir's constant.

The MBE is representing a straight-line relationship as in the following equation:

$$
Y=m X+a
$$

where

$$
\begin{aligned}
& Y=G_{p}+B_{w} W_{p} E_{g} \\
& X=1359.7 \rho_{B}\left(G_{c}-V\right)-7758 \phi\left(1-S_{w i}\right) \\
& m=A h=\text { The slope } \\
& a=7758 A h \phi\left(1-S_{w i}\right) E_{g i}=\text { The intercept. }
\end{aligned}
$$

(2) Including rock and fluid compressibility:

$$
G_{P}+\frac{B_{w w} W_{P} E_{g}}{1-\left(c_{f} \Delta P\right)}=A h\left\{1359.7 \rho_{B}\left(G_{c}-\frac{V_{m} b P}{1+b P}\right)+\frac{7758 \phi\left[\Delta P\left(c_{f}+S_{w i} c_{w i}\right)-\left(1-S_{w i}\right)\right] E_{g}}{1-\left(c_{f} \Delta P\right)}\right\}+7758 A h \phi\left(1-S_{w i}\right) E_{g i}
$$

Similar to the first case, the previous equation represents a straight-line relationship as in the $(Y=m X+a)$ equation.

In the two cases of Ahmed's method, plotting the resulted values of $X$ and $Y$ from the available production data will lead to predicting the drainage area $A$ by using the $(Y=m X+a)$ equation. After this, the resulting drainage area $A$ will be used to calculate the initial gas in place (IGIP) as the summation of free and sorbed gases: 


\section{Moghadam Method}

Moghadam developed another form of material balance equations [68]. The objective of the new form was to create a more generalized form of the material balance equation by adding expansion and aquifer support. Moghadam's method uses the approach of plotting $P / Z^{* *}$ vs. $G_{p}$ instead of $P / Z$, in which he modifies the total compressibility equation as following:

$$
Z^{* *}=\frac{p}{\left[\frac{1}{S_{g i}} \frac{p}{Z}\left(S_{g i}-c_{\text {wip }}-c_{e p}-c_{d}\right)+\frac{p_{i}}{Z_{i}}\left(\frac{G}{G_{f}}-1\right)\right] \frac{G_{f}}{G}}
$$

where the effective compressibility is linked to the gas compressibility factor for the unconventional gas reservoir that was derived by King's method by the following equation:

$$
Z^{* *}=Z^{*}\left(\frac{Z_{i}}{Z_{i}^{*}}\right)
$$

Similar to Ahmed's method, Moghadam method can be represented by a straight-line relationship equation $(Y=m X+a)$ as follows:

$$
G_{f} B_{g i}=\left(G_{f}-G_{p}\right) B_{g}+\left(W_{e}-W_{p} B_{w}\right)+\frac{G_{f} B_{g i}}{S_{g i}}\left(c_{f}+c_{w} S_{w i}+c_{o} S_{o i}\right)\left(p_{i}-p\right)+\rho_{B} B_{g} \frac{G_{f} B_{g i}}{S_{g i} \phi}\left(\frac{V_{L} p_{i}}{p_{L}+p_{i}}-\frac{V_{L} p}{p_{L}+p}\right)
$$

The previous equation can be simplified as the following equation:

$$
\frac{p}{Z}\left(S_{g i}-c_{\text {wip }}-c_{e p}-c_{d}\right)=\frac{p_{i}}{Z_{i}}\left(1-\frac{G_{p}}{G_{f}}\right) S_{g i}
$$

From the previous equation, the value of $G_{f}$ can be predicted by plotting $\frac{p}{Z}\left(S_{g i}-c_{w i p}-c_{e p}-c_{d}\right)$ vs. $G_{p}$, where $G_{f}$ value is the intercept of the straight line with the $x$-axis. After this, the resulting value $G_{f}$ should be used in the following equation:

$$
G=G_{f}+\frac{G_{f} B_{g i}}{S_{g i}} \frac{\rho_{B}}{\phi} \frac{V_{L} p_{i}}{p_{L}+p_{i}}
$$

This will lead to an estimated value of $Z^{* *}$. By plotting $P / Z^{* *}$ vs. $G_{p}$ based on the following equation, the initial gas in place can be estimated from the intercept with the straight line.

$$
\frac{p}{Z^{* *}}=\left(1-\frac{G_{p}}{G}\right) \frac{p_{i}}{Z_{i}^{* *}}
$$

The resulting straight-line plot of $P / Z^{* *}$ vs. $G_{p}$ from the previous equation should provide similar results to the $P / Z$ vs. $G_{p}$ in conventional resources, where

$G_{f}=$ Free gas in place, Bcf

$c_{d}=$ Relative volume change caused by CBM gas desorption

$c_{0}=$ Oil compressibility, $\mathrm{psia}^{-1}$

$c_{\text {wip }}=$ Relative volume change caused by water influx and production

$c_{e p}=$ Relative volume change caused by residual fluid and formation.

\section{Watson Method}

In 2013, Watson [74] derived a new material balance equation model for CBM. In this method, Watson used the Havlena-Odeh method to include water invasion and water production in his model. These factors affect gas desorption by decreasing the reservoir pressure, which will eventually affect 
the gas production. In addition, Watson considered both free gas content and adsorbed gas in his calculation for the initial gas in place of CBM, which is given by the following equation:

$$
G_{i}=A h\left[\frac{43560 \phi_{f}\left(1-S_{w f i}\right)}{B_{g i}}+1.359 C_{g i} \rho_{c}\left(1-f_{a}-f_{m}\right)\right]
$$

The material balance equation from Watson method is given by the following equation, where he created a comparison between the historical production performance and the predicated production performance to confirm the validity of his method. In addition, he used the non-linear regression technique to get more accurate results.

$$
G_{i} B_{g}+W_{p}=\sum_{k} J\left(P_{i}-P_{k}\right) \Delta t_{k}+\Delta p W_{i}\left(c_{w}+c_{f}\right)+\frac{W_{i} B_{g}}{7758 \phi}\left\{1.359 \rho_{c}\left[V_{L}\left(1-f_{a}-f_{m}\right)\left(\frac{P_{d}}{\left(P_{d}+P_{L}\right)}-\frac{P}{\left(P_{d}+P_{L}\right)}\right)\right]\right\}
$$

where

$J=$ Aquifer productivity index, $\mathrm{gm} / \mathrm{cm}^{3}$

$P_{d}=$ Desorption pressure, psia

$S_{w f i}=$ Initial water saturation for the interconnected fractures, fraction

$f_{a}=$ Average weight fraction of ash, fraction

$f_{m}=$ Average weight fraction of moisture, fraction

$W_{i}=$ Initial water in the drainage area

$\rho_{c}=$ Pure coal density, $\mathrm{gm} / \mathrm{cm}^{3}$.

\subsection{Comparison between the Different Methods of Predicating the IGIP for CBM}

The discussed methods have some similarities and differences. The selection of the method used should be based on the available type of data and the stage of the analysis. For example, the volumetric method can be used during the exploration stage, but it includes a high percentage of uncertainty due to the lack of accurate data. On the other hand, the decline curve method can provide the future performance of the gas production, but it has a difficulty in predicting the performance during the transient flow period. The material balance equation method can also include the different factors affecting gas production, but it requires the allocation of gas production data for a long period [54]. Moreover, material balance equations, as listed, heavily rely on Langmuir parameters; they should be approached with caution for multicomponent systems, where Langmuir or even extended Langmuir may associate some deficiency. Table 5 demonstrates the advantages and disadvantages of each method.

\begin{tabular}{|c|c|c|}
\hline Method & Advantages & Disadvantages \\
\hline$\underline{\text { Volumetric Method }}$ & $\begin{array}{l}\text { - } \quad \text { Can be implemented during the } \\
\text { exploration stage. } \\
\text { - } \quad \text { Important for reserves estimation. } \\
\text { - } \quad \text { Does not require production data. } \\
\text { - } \quad \text { Avoid production operation cost. }\end{array}$ & $\begin{array}{l}\text { - Inaccurate results due to the } \\
\text { uncertainty of data. } \\
\text { - } \quad \text { Difficult to applied at well level. }\end{array}$ \\
\hline Decline Curve Method & 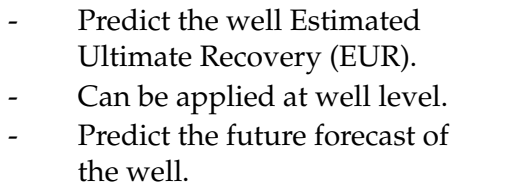 & $\begin{array}{l}\text { - } \quad \text { Requires historical production data. } \\
\text { - } \quad \text { Requires Rate Transient Analysis } \\
\text { (RTA) data. } \\
\text { - Including a percentage of inaccuracy } \\
\text { for the transient flow period. }\end{array}$ \\
\hline
\end{tabular}

Table 5. Comparison between the IGIP predicting methods. 
Table 5. Cont.

\begin{tabular}{clll}
\hline \multicolumn{1}{c}{ Method } & \multicolumn{1}{c}{ Advantages } & \multicolumn{1}{c}{ Disadvantages } \\
\hline & - & Predict the gas reserves. & Requires a long period of \\
Material Balance Equation & - & Predict the well Estimated & Ultimate Recovery (EUR). \\
& & Consideration for different gas data. \\
& reservoir types. & $-\begin{array}{l}\text { Requires measurements of different } \\
\text { gas reservoir parameters. }\end{array}$ \\
\hline
\end{tabular}

\section{CMB Recovery Methods}

The primary key for coalbed methane (CBM) recovery is decreasing the reservoir pressure. The decline in the reservoir pressure allows for the methane desorption from the coal to the natural fractures due to the pressure difference. This driving mechanism is considered the primary mechanism for methane recovery. This mechanism can achieve up to 50\% recovery of the total available methane in the reservoir [75].

Recently, several methods have been developed in order to enhance the recovery of the coalbed methane, such as injecting $\mathrm{CO}_{2}, \mathrm{~N}_{2}$, or a mixture of both into the coal seams. The objective of using the gas injection to produce CBM is to reduce the partial pressure of methane, which decreases the required time for the desorption process [76].

The first trial of improving the recovery of the coalbed methane was conducted in the United States in 2000 [77]. This test was conducted by injecting carbon dioxide $\left(\mathrm{CO}_{2}\right)$ from four (4) injection wells, which resulted in increasing the recovery of the CBM from $77 \%$ to $95 \%$. After this, several attempts of using $\mathrm{CO}_{2}$ injection to increase the $\mathrm{CBM}$ recovery have been carried out in Poland, Canada, and Japan. These trials exhibited an increase in the recovery ratio of the CBM. Accompanied by this increase in CBM production, there was the disadvantage of the permeability reduction, which was caused by the coal swelling. The reason for this reduction in the reservoir permeability is the fast adsorption of $\mathrm{CO}_{2}$ by coal. In some cases, the damage caused by $\mathrm{CO}_{2}$ injection could reduce the reservoir permeability by two orders of magnitude, especially around the $\mathrm{CO}_{2}$ wells' injection wells [78].

After this, another approach was tested to enhance the recovery of CBM, which is injecting nitrogen $\left(\mathrm{N}_{2}\right)$. The idea of injecting $\mathrm{N}_{2}$ was the target of overcoming the permeability reduction that was encountered with injecting $\mathrm{CO}_{2}$, where $\mathrm{N}_{2}$ adsorption affinity to coal is lower than methane. This means that injecting $\mathrm{N}_{2}$ can decrease the methane partial pressure, which leads to accelerating the gas desorption from coal, and eventually it causes an expansion in the coal permeability. The conducted trials indicated an increment in the CBM production by $20 \%$ of the original recovery. On the other hand, the approach of injecting $\mathrm{N}_{2}$ approach encountered an early breakthrough in production that was caused by the adsorption affinity of $\mathrm{N}_{2}$ to methane. This requires adding additional charges for production operation in order to separate the methane from $\mathrm{N}_{2}$. Moreover, the exhibited production period from $\mathrm{N}_{2}$ injection was shorter than the period of $\mathrm{CO}_{2}$ injection [79].

A new approach of injecting a mixture of the two gases $\left(\mathrm{CO}_{2}\right.$ and $\left.\mathrm{N}_{2}\right)$ was proposed after this. In Canada, Mavor et al. conducted experiments of injecting flue gas, which is $\mathrm{N}_{2} / \mathrm{CO}_{2}$ mixture. From his experiments, Mavor et al. [80] concluded that the flue gas could effectively improve the permeability of coal. After this, Jessen et al. [81] developed the idea of ternary gases $\left(\mathrm{CH}_{4}, \mathrm{CO}_{2}\right.$, and $\left.\mathrm{N}_{2}\right)$ displacement, where he managed to implement this approach by numerical simulations since the ternary gases have complex coupling responses. Sayyafzadeh et al. [82] achieved an enhancement of the recovery ratio of CBM by $21.1 \%$ more than the original recovery mechanism, where he used a semisynthetic simulation model to prepare a mixture of gases with less $\mathrm{CO}_{2}$. The negative side of Sayyafzadeh's approach is neglecting effects on coal permeability, but the results of his numerical simulation led to establishing the basis of improving the CBM recovery.

Besides these attempts, other studies were conducted by considering different coal reservoir parameters, several compositions of gas mixtures, and concentrations of mixed gases in order to reveal the coupling mechanism of the ternary gases $\left(\mathrm{CH}_{4}, \mathrm{CO}_{2}\right.$, and $\left.\mathrm{N}_{2}\right)$. Establishing the coupling 
mechanism can lead to predicting the most effective approach for developing a certain coalbed methane reservoir [76].

\section{CBM Resources Development Challenges}

There are several challenges facing the CBM industry. Some of these challenges are specific to certain parts of the world, but the major concerns facing the development of CBM resources are shared worldwide. In addition to the complex geological conditions and production technology constraints, the CBM industry still faces other major challenges leading to higher operation costs and low return on investment (ROI). Since 2013, CBM exploration and development has slowed down due to the fluctuating global energy markets, restricted policies, and other development challenges [83]. The following are some of the challenges that accompany the development and production of CBM.

\subsection{CBM EEP Technological Constraints}

The aspect of producing from unconventional resources was not considered by many of the hydrocarbon producers in the world until the last decades. The idea of utilizing CBM as an energy source was introduced in the USA. The beginning of the research was not focused on the production of the CBM to provide energy, but it was concerned mainly with the mine safety. The production methods of the CBM were therefore not implemented comprehensively on many reservoirs with different characterizations, and they were significantly limited to USA fields until recent years. In addition, the complex geological features and reservoir characteristics encountered in the USA fields may not be the same for the other fields in the world. Since the gained knowledge of handling the CBM reservoirs was obtained from the challenges in the USA only, a variety of geological issues should be considered. Due to the complexity and the lack of experience with unconventional resources compared the conventional ones, there are many challenges that require using the suitable technology in order to start the production [10].

CBM E\&P is relatively young, and further development of its technologies is needed. The multi-process drainage recovery of CBM that undergoes a drainage-depressurization-desorptiondiffusion-percolation processes leads to the restriction of CBM production in each stage. This restriction of production will lead to a long drainage cycle, low well productivity, and long duration to reach the targeted production. Therefore, the current stimulation technologies need further improvements to avoid these issues [84].

\subsection{Environmental Challenges}

As the interest in utilizing CBM as a new source of natural gas has increased recently, new environmental concerns have been raised that are associated with the development of the CBM reservoirs. CBM extraction can increase the methane released into the atmosphere, causing several environmental problems such as global warming, tropospheric ozone formation, and stratospheric ozone depletion. The environmental issues related to the extraction of the CBM can vary during the different stages of the production. It can start from the exploration, during the field and the facility development, and continue through the production operations. With the exploration phase, managing the drilling fluids during the drilling of the exploration wells might be difficult due to the ambiguity of this phase. As for the development phase, the environmental effect could be bigger because it includes working on different sites with highly intense activity at the same time. The production operation has a major influence on the environment, where it requires the management of the produced water, water treatment, and water disposal that accompany CBM production. Large quantities of water have to be removed from the coal to decrease the pressure initiating methane desorption. Therefore, the cost of water disposal and treatment is critical in the investment decisions associated with CBM [85].

Another environmental challenge that CBM industry has to address is the large surface footprint that is created due to the density of wells and the surface infrastructure requirements. To obtain maximum recovery, unlike the production of conventional oil and gas, production of CBM requires 
drilling and development of several wells with small well spacing. This proximity of wells is crucial to facilitate depressurizing the seam and initiating the desorption of methane from the coal matrix [85]. This high density of wells leads to great land disturbance at different levels, including construction activities, access roads, and the increased density of pipelines connecting the wells [86]. Furthermore, this land disturbance could lead to significant soil disturbance, which could be further contaminated by the CBM waters that are discharged into unbounded reservoirs and allow water to penetrate into the subsurface or percolate into the surrounding soil [87].

There is always the claim that utilizing the CBM instead of other traditional energy resources has positive effects on the environment as it helps in reducing methane emission to the atmosphere. This part of methane reduction is only limited to removing the gas that could be produced during the coal mining process. Otherwise, the production of CBM has an equal environmental impact to the other energy resources in this matter [10].

\subsection{Economic Evaluation Concerns}

Similar to conventional resources, the development of unconventional resources including CBM requires economic considerations. In fact, they require more thinking from the economical side than conventional resources because of the cost factor associated with the stimulation treatments [88].

One of the issues that need to be studied is the infrastructure of field development and gas transportation. The development of this type of energy resource requires systematic spacing between the drilled wells to achieve the most optimized production rates, which requires a sufficient field area to be achieved. The transportation of natural gas is constrained by the pipeline capacity, where locating pipelines with the appropriate size is not an option in all fields. In addition, there is always the cost for the required technologies to start producing from the field such as hydraulic fracturing and stimulation jobs [88].

In order to evaluate any prospect of CBM economically, there are certain parts besides the capital and operations costs that need to be analyzed, which are the gas resources, gas reserves, and gas deliverability. These three parts depend on different factors that need to be included in the economic analysis in order to provide a clear judgment and justification of any CBM prospect [89].

In the case of gas resources, CBM is one of the unconventional resources for natural gas. This means that the production of CBM requires massive treatments to the gas reservoir in order to be economically profitable. In addition, other production methods need to be considered in the development stage of the gas reservoir in the case of unconventional resources. For example, well spacing can be challenging in some fields due to the lack of free land [90].

Reserves are those quantities that are anticipated to be commercially recoverable under defined conditions. Generally, calculating the reserves of hydrocarbons is based on the information from different resources. This information provides several measurements that are used to estimate the reserve of hydrocarbons in a reservoir. The provided measurements can be divided into two types, which are known and assumed. These measurements are considered based on the available geological and engineering information. Unfortunately, the estimation of the reserves based on the assumed measurements is not commercially viable in all situations. The estimation of the CBM deposits depends mainly on the exploration data and assumptions due to the lack of historical data. In addition, the nature of the CBM reservoirs is more complex and very hard to model. Therefore, it is more difficult to estimate the reserves of CBM than conventional hydrocarbons. Due to this uncertainly in the reserve estimation, several questions will be raised about the value of the investment in new CBM prospects, and it could lead to a decrease in the demand for investing in CBM production [91].

The estimation of the reserves is a critical part of the economical evaluation of a CBM reservoir, where calculating the reserves is the key to determine the profitability of the target prospect. As mentioned in the section on the methods of predicting IGIP, there are several factors that could affect the estimation of the reserves, and selecting the suitable method for estimating the reserves is essential in this process. 
As for gas deliverability, it starts from the ability to drive the gas from the natural fractures to the wellbore, which requires an accurate prediction of the properties in the coal fracture system. Furthermore, there are other requirements for methane production such as low-pressure pipelines, water disposal facilities, and natural gas liquids (NGL) plant. In the analysis of these costs, different conditions need to be considered as the capacity of the plants and the pipelines and the distance for the gas to be transmitted [88].

By analyzing these three major parts of CBM development and taking into account the average present and expected gas prices, an economical evaluation for the CBM reservoir can be conducted. Due to the complexity of CBM development projects, the capital costs (CAPEX) and the operation costs (OPEX) have to be evaluated and determined precisely to achieve successful development [88].

\section{Conclusions}

This study is a general review of the CBM, including the aspects of reservoir characterization, developed technologies, reserves estimation, and challenges of the field development. Focusing on the methods of predicting the Initial Gas in Place (IGIP), there were several methods that have to be developed to estimate the IGIP. These methods have strong parts and weak parts due to the complexity and ambiguity of the CBM formations. Some of these methods are simple, such as the volumetric method, and others are more accurate, such the Material Balance Equation (MBE). Each of these methods includes several models, which are developed based on previous models. Inthe end, the selection for each of these methods is dependent on the type of available data and the stage of the CBM reservoir development.

Author Contributions: Original draft preparation, A.A. (Ali Altowilib), A.A. (Ahmed AlSaihati) and H.A.; writing-review and editing, A.A. (Ali Altowilib), A.A. (Ahmed AlSaihati), H.A., S.A. (Saad Alafnan), and S.A. (Sulaiman Alarifi); supervision, S.A. (Saad Alafnan); project administration, S.A. (Saad Alafnan). All authors have read and agreed to the published version of the manuscript.

Funding: This research received no external funding.

Conflicts of Interest: The authors declare no conflict of interest.

\section{References}

1. Hannah Ritchie and Max Roser (2020)_ “Energy”. Available online: https://ourworldindata.org/energy (accessed on 10 November 2020).

2. Chakhmakhchev, A. Worldwide Coalbed Methane Overview. In SPE Economics and Evaluation Symposium; SPE: Richardson, TX, USA, 2007. [CrossRef]

3. U.S. Department of Energy, Energy Information Administration, Independent Statistics \& Analysis. 4 December 2020. Available online: https://www.eia.gov/dnav/ng/ng_prod_coalbed_s1_a.htm (accessed on 10 November 2020).

4. Dallegge, T.A.; Barker, C.E. Coal-Bed Methane Gas-In-Place Resource Estimates Using Sorption Isotherms and Burial History Reconstruction: An Example from the Ferron Sandstone Member of the Mancos Shale, Utah. Chapter L of Geologic Assessment of Coal in the Colorado Plateau: Arizona, Colorado, New Mexico, and Utah. Available online: https://pubs.usgs.gov/pp/p1625b/Reports/Chapters/Chapter_L.pdf (accessed on 10 November 2020).

5. Tremain, C.M.; Laubach, S.E.; Whitehead, N.H., III. Fracture (Cleat) Patterns in Upper Cretaceous Fruitland Formation Coal Seam, San Juan Basin; Ayers, W.B., Kaiser, W.R., Eds.; Coalbed Methane in the Upper Cretaceous Fruitland Formation, New Mexico Bureau of Mines and Mineral Resources Bulletin: Socoroo, NM, USA, 1994; Volume 146, pp. 87-102.

6. Puri, R.; Yee, D. Enhanced coal-bed methane recovery: New Orleans, Society for Petroleum Engineers 20732. In Proceedings of the Society of Petroleum Engineers 65th Annual Technical Conference and Exhibition, New Orleans, LA, USA, 23-26 September 1990; Volume 65, pp. 193-202.

7. Krevelen, D.W. Coal: Typology, Chemistry, Physics, Constitution; Elsevier Publishing Co.: New York, NY, USA, 1961. 
8. Airey, E. Gas emission from broken coal. An experimental and theoretical investigation. Int. J. Rock Mech. Min. Sci. Géoméch. Abstr. 1968, 5, 475-494. [CrossRef]

9. Clarkson, C.R. Production data analysis of unconventional gas wells: Review of theory and best practices. Int. J. Coal Geol. 2013, 109, 101-146. [CrossRef]

10. Sloss, L. Coalbed Methane Extraction. 2000. Available online: https://www.researchgate.net/publication/ 337486500_Coalbed_methane_extraction (accessed on 10 November 2020). [CrossRef]

11. Widera, M. What are cleats? Preliminary studies from the Konin lignite mine, Miocene of central Poland. Geologos 2014, 20, 3-12. [CrossRef]

12. Mastalerz, M.; Drobniak, A.; Hower, J.C.; Okeefe, J.M.K. Spontaneous Combustion and Coal Petrology. In Coal and Peat Fires: A Global Perspective; Elsevier BV: Amsterdam, The Netherlands, 2011; pp. 47-62.

13. Stach, E.; Mackowsky, M.-T.; Teichmüller, M.; Taylor, G.H.; Chandra, D.; Teichmüller, R. Stach's Textbook of Coal Petrology, 3rd ed.; Gerbrüder Bortraeger: Berlin, Germany, 1982; 535p.

14. Scott, A.C.C.F.K. Diessel 1992. Coal-Bearing Depositional Systems; Price DM 198.00 (hard covers); Springer: Berlin/Heidelberg, Germany; New York, NY, USA; London, UK; Paris, France; Tokyo, Japan; Hong Kong, 1992; p. xiv + 721. ISBN 354052516.

15. Jenkins, C.D.; Freyder, J.S.; Starley, G. “Chapter 6: Coalbed Methane” Petroleum Engineering Handbook, Volume 6: Emerging and Peripheral Technologies; Warner, H.R., Jr., Richardson, T.X., Eds.; Editor-In-Chief L.W. Lake; Society of Petroleum Engineers: London, UK, 2007.

16. Scott, A. Review-Article. Geol. Mag. 1994, 131, 140. [CrossRef]

17. Wallace, J.A. Coalbed methane production -an operator's perspective. In Coalbed Methane in Alberta What's It All About? Nikols, D., Treasure, S., Stuhec, S., Goulet, D., Eds.; ARC Information Series No. 108; Alberta Research Council: Edmonton, AB, Canada, 1990.

18. Zuber, M.D. A Guide to Coalbed Methane Reservoir Engineering; GRI-93/0293; Gas Research Inst. (Gas Technology Inst.): Chicago, IL, USA, 1996.

19. Usman, T.; Babagana, G.; Al-Harbi, M. Well-Testing CBM-Wells Definition of Major Anomalies with Oil and Gas Reservoir. J. Eng. Res Technol. 2015, 4.

20. Song, L.; Martin, K.; Carr, T.R.; Ghahfarokhi, P.K. Porosity and storage capacity of Middle Devonian shale: A function of thermal maturity, total organic carbon, and clay content. Fuel 2019, 241, 1036-1044. [CrossRef]

21. Song, L.; Carr, T.R. The pore structural evolution of the Marcellus and Mahantango shales, Appalachian Basin. Mar. Pet. Geol. 2020, 114, 104226. [CrossRef]

22. AlAfnan, S.; Sølling, T.; Mahmoud, M. Effect of Kerogen Thermal Maturity on Methane Adsorption Capacity: A Molecular Modeling Approach. Molecule 2020, 25, 3764. [CrossRef]

23. ASTM D388-88. Standard Classification of Coals by Rank. Annual Book of ASTM Standards, Part 26; ASTM: West Conshohocken, PA, USA, 1979.

24. Hughes, B.D.; Logan, T.L. How to Design a CBM Well. Pet. Eng. Int. 1990, 16, 15-19.

25. Carlos, A.M. Comparison of Computation Methods for CBM Production Performance. Master's Thesis, University of Texas A\&M, College Station, TX, USA, 2007.

26. Roberts, L.N.; Biewick, L. Geologic Assessment of Coal in the Colorado Plateau: Arizona, Colorado, New Mexico, and Utah; Professional Paper; Geological Survey: Reston, VA, USA, 2000.

27. Keshavarz, A.; Sakurovs, R.; Grigore, M.; Sayyafzadeh, M. Effect of maceral composition and coal rank on gas diffusion in Australian coals. Int. J. Coal Geol. 2017, 173, 65-75. [CrossRef]

28. Awan, F.U.R.; Keshavarz, A.; Akhondzadeh, H.; Al-Anssari, S.F.; Al-Yaseri, A.Z.; Nosrati, A.; Ali, M.; Iglauer, S. Stable Dispersion of Coal Fines during Hydraulic Fracturing Flowback in Coal Seam Gas Reservoirs-An Experimental Study. Energy Fuels 2020, 34, 5566-5577. [CrossRef]

29. Ayoub, J.; Hinkel, J.; Johnston, D.; Levine, J. Learning to produce coalbed methane. Oilfield Rev. 1991, 3, $27-40$.

30. Hollub, V.A.; Schafer, P.S. A Guide to Coalbed Methane Operations; Gas Research Institute: Chicago, IL, USA, 1992.

31. Boyer, C.M., II; Zebrowitz, M.J. Coalbed methane completions undergo major evolution. Am. Oil Gas Rep. 1990, 30, 25-28.

32. Lambert, S.W. Comparison of open hole, slotting and perforating completion methods for multiseam coalbed gas wells. In Proceedings of the 1989 Coalbed Methane Symposium Proceedings, Tuscaloosa, AL, USA, 17-20 April 1989; University of Alabama: Tuscaloosa, AL, USA, 1989; pp. 253-264. 
33. Ertekin, T.; Sung, W.; Bilgesu, H.I. Structural properties of coal that control coalbed methane production. In Geology in Coal Resource Utilization; Peters, D.C., Ed.; TechBooks: Fairfax, VA, USA, 1991; pp. 105-124.

34. Young, G.B.C.; McElhiney, J.E.; Paul, G.W.; McBane, R.A. An analysis of Fruitland coalbed methane production, Cedar Hill field, northern San Juan basin. In Proceedings of the 66th Annual Technical Conference and Exhibition of the Society of Petroleum Engineers-S reservoir Engineering, Dallas, TX, USA, 6-9 October 1991; SPE 22913. Society of Petroleum Engineers: Richardson, TX, USA, 1991; pp. 263-276.

35. Zuber, M.D.; Kuuskraa, V.A. Optimizing Well Spacing and Hydraulic-Fracture Design for Economic Recovery of Coalbed Methane. SPE Form. Eval. 1990, 5, 98-102. [CrossRef]

36. Logan, T.L. Proving dynamic open-hole completion techniques in the San Juan Basin. Q. Rev. Methane Coal Seams Technol. 1994, 11, 13-26.

37. Zhang, J.; Si, L.; Chen, J.; Kizil, M.; Wang, C.; Chen, Z. Stimulation Techniques of Coalbed Methane Reservoirs. Geofluids 2020, 2020, 1-23. [CrossRef]

38. Valliappan, V.; Remmers, J.J.C.; Barnhoorn, A.; Smeulders, D.M.J. A Numerical Study on the Effect of Anisotropy on Hydraulic Fractures. Rock Mech. Rock Eng. 2017, 52, 591-609. [CrossRef]

39. Guanhua, N.; Kai, D.; Shang, L.; Qian, S. Gas desorption characteristics effected by the pulsating hydraulic fracturing in coal. Fuel 2019, 236, 190-200. [CrossRef]

40. Li, Q.; Lin, B.; Zhai, C. The effect of pulse frequency on the fracture extension during hydraulic fracturing. J. Nat. Gas Sci. Eng. 2014, 21, 296-303. [CrossRef]

41. Xu, Y.; Zhai, C.; Hao, L.; Sun, X.; Liu, Y.; Li, X.; Li, Q. The Pressure Relief and Permeability Increase Mechanism of Crossing-Layers Directional Hydraulic Fracturing and Its Application. Procedia Eng. 2011, 26, 1184-1193. [CrossRef]

42. Keshavarz, A.; Badalyan, A.; Carageorgos, T.; Bedrikovetsky, P.; Johnson, R. Stimulation of coal seam permeability by micro-sized graded proppant placement using selective fluid properties. Fuel 2015, 144, 228-236. [CrossRef]

43. Pu, W.; Bi, Y. Permeability improvement gas drainage technology with deep borehole accumulated energy hydraulic blasting of low permeability seam. Coal Sci. Technol. 2014, 42, 37-40.

44. Qin, L.; Zhai, C.; Liu, S.; Xu, J. Mechanical behavior and fracture spatial propagation of coal injected with liquid nitrogen under triaxial stress applied for coalbed methane recovery. Eng. Geol. 2018, 233, 1-10. [CrossRef]

45. Abdulrahman, M.M.; Meribout, M. Antenna array design for enhanced oil recovery under oil reservoir constraints with experimental validation. Energy 2014, 66, 868-880. [CrossRef]

46. Jabbour, C.; Quintard, M.; Bertin, H.; Robin, M. Oil recovery by steam injection: Three-phase flow effects. J. Pet. Sci. Eng. 1996, 16, 109-130. [CrossRef]

47. AlAfnan, S.; Sultan, A.S.; Aljaberi, J. Molecular Fractionation in the Organic Materials of Source Rocks. ACS Omega 2020, 5, 18968-18974. [CrossRef] [PubMed]

48. AlAfnan, S.; Aljawad, M.S.; Glatz, G.; Sultan, A.S.; Windiks, R. Sustainable Production from Shale Gas Resources through Heat-Assisted Depletion. Sustainability 2020, 12, 2145. [CrossRef]

49. AlAfnan, S.; Falola, Y.; Al Mansour, O.; Alsamadony, K.; Awotunde, A.; Aljawad, M.S. Enhanced Recovery From Organic-Rich Shales through Carbon Dioxide Injection: Molecular-Level Investigation. Energy Fuels 2020. [CrossRef]

50. AlAfnan, S.; Aljawad, M.; Alismail, F.; Almajed, A. Enhanced Recovery from Gas Condensate Reservoirs through Renewable Energy Sources. Energy Fuels 2019, 33, 10115-10122. [CrossRef]

51. Feasibility, G.T. Research on the permeability improve by coal acidification. Coal Sci. Technol. 2014, 42, 137-141.

52. Zhou, F.; Fredericks, L.; Luft, J.; Oraby, M.; Jeffries, M.; Pinder, B.; Keogh, S. A case study of mapping igneous sill distribution in coal measures using borehole and 3D seismic data. Int. J. Coal Geol. 2020, 227, 103531. [CrossRef]

53. Jie, H.; Changchun, Z.; Zhaohui, H.; Liang, X.; Yuqing, Y.; Guohua, Z.; Wenwen, W. Log evaluation of a coalbed methane (CBM) reservoir: A case study in the southern Qinshui basin, China. J. Geophys. Eng. 2014, 11, 15009. [CrossRef]

54. Kalam, S.; Khan, R.A.; Baig, M.T.; Al-Hashim, H.S. A Review of Recent Developments and Challenges in IGIP Estimation of Coal Bed Methane Reservoirs. SPE Saudi Arabia Sect. Tech. Symp. Exhib. 2015, 178022. [CrossRef] 
55. Caldwell, R.; Heather, D. How to evaluate hard-to-evaluate reserves (includes associated papers 23545 and 23553). J. Pet. Technol. 1991, 43, 998-1003. [CrossRef]

56. Nelson, C.R. Effects of Coalbed Reservoir Property Analysis Methods on Gas-In-Place Estimates. In Proceedings of the SPE Eastern Regional Conference and Exhibition, SPE-57443-MS, Charleston, WV, USA, 21-22 October 1999.

57. Pope, J.; Buttry, D.; Lamarre, R.; Noecker, B.; MacDonald, S.; La Reau, B.; Malone, P.; Van Lieu, N.; Petroski, D.; Accurso, M.; et al. Downhole Geochemical Analysis of Gas Content and Critical Desorption Pressure for Carbonaceous Reservoirs*; (Mar 2007), SPE-111091-MS. Publ.-West Texas Geol. Soc. 2006, 115, 115.

58. Carlson, F.M. Technical and Economic Evaluation of Undersaturated Coalbed Methane Reservoirs; Society of Petroleum Engineers (SPE): Richardson, TX, USA, 2006.

59. Mora, C.; Wattenbarger, R. Comparison of Computation Methods for CBM Performance. J. Can. Pet. Technol. 2009, 48, 42-48. [CrossRef]

60. Arps, J. Analysis of Decline Curves. Trans. AIME 1945, 160, 228-247. [CrossRef]

61. Seshadri, J.N.; Mattar, L. Comparison of Power Law and Modified Hyperbolic Decline Methods. In Proceedings of the Canadian Unconventional Resources and International Petroleum Conference, Calgary, AB, Canada, 19-21 October 2010.

62. Okuszko, K.; Gault, B.; Mattar, L. Production Decline Performance of CBM Wells. J. Can. Pet. Technol. 2008, 47. [CrossRef]

63. Can, B.; Kabir, C.S. Probabilistic Performance Forecasting for Unconventional Reservoirs with Stretched-Exponential Model; Society of Petroleum Engineers (SPE): Richardson, TX, USA, 2011.

64. Duong, A.N. An Unconventional Rate Decline Approach for Tight and Fracture-Dominated Gas Wells; Society of Petroleum Engineers (SPE): Richardson, TX, USA, 2010.

65. Johnson, R.H.; Bollens, A. The Loss Ratio Method of Extrapolating Oil Well Decline Curves. Trans. AIME 1927, 77, 771-778. [CrossRef]

66. Ilk, D.; Currie, S.M.; Symmons, D.; Rushing, J.A.; Blasingame, T.A. Hybrid Rate-Decline Models for the Analysis of Production Performance in Unconventional Reservoirs; Society of Petroleum Engineers (SPE): Richardson, TX, USA, 2010.

67. Clark, A.J.; Lake, L.W.; Patzek, T.W. Production Forecasting with Logistic Growth Models. In Proceedings of the SPE Annual Technical Conference and Exhibition, St. Denver, CO, USA, 30 October-2 November 2011.

68. Moghadam, S.; Jeje, O.; Mattar, L. Advanced Gas Material Balance in Simplified Format. J. Can. Pet. Technol. 2011, 50, 90-98. [CrossRef]

69. King, G.R. Material Balance Techniques for Coal Seam and Devonian Shale Gas Reservoirs. In Proceedings of the SPE Annual Technical Conference and Exhibition, SPE-20730-MS, New Orleans, LA, USA, 23-26 September 1990.

70. Jensen, D.; Smith, L.K. A Practical Approach to Coalbed Methane Reserve Prediction Using a Modified Material Balance. In Proceedings of the International Coalbed Methane Symposium, Tuscaloosa, AL, USA, 12-16 May 1997; p. 9765.

71. Seidle, J.P. A Modified p/Z Method for Coal Wells. In Proceedings of the SPE Rocky Mountain Regional Meeting, SPE-55605-MS, Gillette, WY, USA, 15-18 May 1999.

72. Clarkson, C.R.; McGovern, J.M. Study of the potential impact of matrix free gas storage upon coalbed gas reserves and production using a new material balance equation. In Proceedings of the International Coalbed Methane Symposium, the Paper 0113, Tuscaloosa, AL, USA, 14-18 May 2001; pp. 14-18.

73. Ahmed, T.H.; Centilmen, A.; Roux, B.P. A Generalized Material Balance Equation for Coalbed Methane Reservoirs; Society of Petroleum Engineers (SPE): Richardson, TX, USA, 2006.

74. Marshall, W. Havlena Odeh Method Solution for Coalbed Methane Reservoirs. In Proceedings of the Unconventional Resources Technology Conference, Denver, CO, USA, 12-14 August 2013.

75. Song, Y.; Bo, J.; Jie-Gang, L. Nanopore Structural Characteristics and Their Impact on Methane Adsorption and Diffusion in Low to Medium Tectonically Deformed Coals: Case Study in the Huaibei Coal Field. Energy Fuels 2017, 31, 6711-6723. [CrossRef]

76. Fan, N.; Wang, J.; Deng, C.; Fan, Y.; Mu, Y.; Wang, T. Numerical study on enhancing coalbed methane recovery by injecting $\mathrm{N}_{2} / \mathrm{CO}_{2}$ mixtures and its geological significance. Energy Sci. Eng. 2020, 8, 1104-1119. [CrossRef] 
77. Shi, J.Q.; Durucan, S. A numerical simulation study of the Allison Unit $\mathrm{CO}_{2}$-ECBM pilotThe impact of matrix shrinkage and swelling on ECBM production and $\mathrm{CO}_{2}$ injectivity. In Proceedings of the Greenhouse Gas Control Technologies 7; Elsevier BV: Amsterdam, The Netherlands, 2005; Volume I, pp. 431-439.

78. Zhou, F.D.; Hou, W.W.; Allinson, G. A Feasibility Study of ECBM Recovery and $\mathrm{CO}_{2}$ Storage for Producing CBM Field in Southest Qinshui Basin; China. Int. J. Greenh. Gas Control. 2013, 19, 26-40. [CrossRef]

79. Lin, J.; Ren, T.; Cheng, Y.; Nemcik, J.; Wang, G. Cyclic $\mathrm{N}_{2}$ injection for enhanced coal seam gas recovery: A laboratory study. Energy 2019, 188, 116115. [CrossRef]

80. Mavor, M.; Gunter, W.D.; Robinson, J.R. Alberta Mutliwell Micro-Pilot Testing for CBM Properties, Enhanced Recovery and $\mathrm{CO}_{2}$ storage Potential; (Sep 2004). In SPE Annual Technical Conference and Exhibition; Society of Petroleum Engineers: Richardson, TX, USA, 2004; pp. 26-29.

81. Jessen, K.; Tang, G.-Q.; Kovscek, A.R. Laboratory and Simulation Investigation of Enhanced Coalbed Methane Recovery by Gas Injection. Transp. Porous Media 2007, 73, 141-159. [CrossRef]

82. Sayyafzadeh, M.; Keshavarz, A.; Alias, A.R.M.; Dong, K.A.; Manser, M. Investigation of varying-composition gas injection for coalbed methane recovery enhancement: A simulation-based study. J. Nat. Gas Sci. Eng. 2015, 27, 1205-1212. [CrossRef]

83. Tao, S.; Chen, S.; Pan, Z. Current status, challenges, and policy suggestions for coalbed methane industry development in China: A review. Energy Sci. Eng. 2019, 7, 1059-1074. [CrossRef]

84. Li, Y.; Zhou, D.-H.; Wang, W.-H.; Jiang, T.-X.; Xue, Z.-J. Development of unconventional gas and technologies adopted in China. Energy Geosci. 2020, 1, 55-68. [CrossRef]

85. Freij-Ayoub, R. Opportunities and challenges to coal bed methane production in Australia. J. Pet. Sci. Eng. 2012, 88, 1-4. [CrossRef]

86. Griffiths, M.; Severson-Baker, C. The Environmental Challenges of Coalbed Methane Development in Alberta; The Pembina Institute: Drayton Valley, AB, Canada, 2003.

87. Young, A.L. Coalbed Methane: A New Source of Energy and Environmental Challenges. Environ. Sci. Pollut. Res. 2005, 12, 318-321. [CrossRef]

88. Green, I.A.; Ugoji, K.U.; Igbere, B.N. Economic Analysis of Natural Gas Reserves Addition from Coal Bed Methane in Nigeria. Eur. J. Eng. Res. Sci. 2019, 4, 31-34. [CrossRef]

89. Kim, A.G. Estimating Methane Content of Bituminous Coalbeds from Adsorption Data; Report of Investigations; U.S. Bureau of Mine: Washington, DC, USA, 1977.

90. Dhir, R.R.D.; Mavor, J.M. Economics and Reserves of Estimation of Coal-bed Methane Reservoirs; Chapter 8, No. 52; Oil \& Gas Journal: London, UK, 2016.

91. Mavor, M.; Nelson, C.R. Coalbed Reservoir Gas-in-Place Analysis; GRI Gas Research Institute: Des Plaines, IL, USA, 1997.

Publisher's Note: MDPI stays neutral with regard to jurisdictional claims in published maps and institutional affiliations.

(C) 2020 by the authors. Licensee MDPI, Basel, Switzerland. This article is an open access article distributed under the terms and conditions of the Creative Commons Attribution (CC BY) license (http://creativecommons.org/licenses/by/4.0/). 